\title{
A QFD-Based Evaluation Method for Business Models of Product Service Systems
}

\author{
Tianyang Li, ${ }^{1}$ Ting He, ${ }^{2}$ Zhongjie Wang, ${ }^{1}$ and Yufeng Zhang ${ }^{3}$ \\ ${ }^{1}$ School of Computer Science and Technology, Harbin Institute of Technology, Harbin, Heilongjiang 150001, China \\ ${ }^{2}$ College of Computer Science and Technology, Huaqiao University, Xiamen, Fujian 361021, China \\ ${ }^{3}$ Birmingham Business School, University of Birmingham, Birmingham B15 2TT, UK
}

Correspondence should be addressed to Ting He; xuantinghe@hit.edu.cn

Received 2 April 2016; Revised 6 May 2016; Accepted 15 May 2016

Academic Editor: Benoit Iung

Copyright (C) 2016 Tianyang Li et al. This is an open access article distributed under the Creative Commons Attribution License, which permits unrestricted use, distribution, and reproduction in any medium, provided the original work is properly cited.

\begin{abstract}
Organizations have been approaching Product Service Systems (PSS) in unoptimized business model fashions. This is partially because there is ineffective evaluation of PSS business models. Therefore, a more sufficient evaluation method might advance the evaluation of PSS business models and assist organizations that are considering a servitisation strategy. In this paper, we develop a value oriented method by using the Quality Function Deployment (QFD) technique to employ correlations derived from the design information of PSS business models to evaluate these PSS business models. We describe the method applying steps and its practical application in a real life case study. This method improves the formulation of an evaluation step within a design process of PSS business models based on correlations of different dimensions of the PSS value and PSS business models; it allows a balance between the customer value and organization value that are delivered by PSS business models to be made quantitatively. Finally, it fosters the effective utilization of the design information accumulated in the earlier part of the design process to quantitatively evaluate whether a PSS business model is optimized for providing appropriate values for customers and organizations.
\end{abstract}

\section{Introduction}

The pressure of the customer personalization and expectations and the erosion of product margins and intense competition have forced manufacturing companies to transform their product-oriented business in the service domain and offer bundles of products and services to secure additional sources of revenue and profits [1-3]. This phenomenon represents that traditional business models have evolved from a "pure product" orientation toward an integrated Product Service System (PSS) and can be called servitisation of manufacturing [4]. A value-oriented method of evaluating PSS business models for an evaluation step in the design process of PSS business models can be used to effectively support this business model evolution and to respond to the challenges revealed by the servitisation phenomenon $[5,6]$.

Product-services (PS) offerings consist of combinations of physical products, services, and systems that have been integrated and optimized from a lifecycle perspective to pursue the best value for both customers and organizations involved. In order to realize such value, product-based manufacturers have to significantly redesign their organizational principles, structures, and processes [7] as well as their capabilities [8] and relationships with customers and suppliers $[9,10]$ to transform to a new business model for delivering PS offerings. However, this business model transformation leads to a series of bankrupt risks [11]. Most companies fail to implement this business model transformation, falling into the so-called "service paradox" [11]. The "service paradox" describes situations in which companies have invested heavily in extending their service business to increase their service offerings while incurring higher costs and without any realized returns. The current corporate processes of designing PSS business models in many manufacturing companies have not used an available method in an assessment step to quantitatively evaluate whether the designed or redesigned organization structures, processes, and partner network, as well as cost arrangement in the new business model for 
PS offering, are optimized to be implemented for meeting customer value demands and providing desired revenues to companies themselves $[12,13]$. In this situation, common difficulties include poorly defining the structure of PSS business models and costs, vague returns and customers' satisfactions prediction, and a dearth of relevant processes needed to support the quantitative analysis and optimization of redesigned PSS business models and may finally lead to the "service paradox" [12].

To overcome these gaps, creating a value-oriented evaluation method used in the design process of PSS business models must first be undertaken [10,13]; this method should be available to support designers to effectively and quantitatively evaluate the feasibility or optimization of different types of PSS business models according to establishing correlations between parameters of PSS business models and dimensions of customer value by using the data of design information [14] and then evaluating and optimizing the redesigned PSS business model with readjusting these correlations.

Despite the importance of providing a value-oriented evaluation method, the current literature only refers to the value-oriented methods for evaluating PSS components, PS offerings, or single dimensions of PSS business models to gain strategic, marketing, or operational insights [15-18]. Particularly, some QFD technique based methods have been developed to discuss specific managerial aspects on partial dimensions of PSS business models, including characteristics of PS offerings [15], suppliers [16], customer requirement [17], or manufacturing process [18], and therefore have a narrow focus for evaluating PSS business models. However, providing an effective and efficient evaluation method that captures all the dimensions of both the PSS value and PSS business model can assist in understanding the proper structure and nature of PSS business models and its capability of value generation for both customers and organizations, especially in the design process which is important $[12,13,19]$.

Currently there is no comprehensive method that quantitatively evaluates business models of PSS in the literature. The lack of the literature precedent raises three questions. (i) What are dimensions of the PSS value and PSS business models that are used in the evaluation method? (ii) How might correlations of these dimensions be established, verified, and used to reflect and evaluate the designed value of PSS business models? (iii) How might evaluation criteria and functions be established in a comprehensive way?

Therefore, we propose an innovative value-oriented evaluation method that may be used in both business-to-business (B2B) and business-to-consumer (B2C) domains. While using quantitative measures and design information, the method will evaluate the feasibility of a PSS business model by mapping its capability of value delivery to customer value and seeing how well the two fit and how about the margins of organizations. The method is inspired by QFD technique and its related dimensions are derived from literature data; in addition, a case example involving one of the biggest manufacturers of China in the home appliance industry is used to illustrate the application of this method in a realworld context.
The remainder of this paper contains a literature review that considers the theoretical links between PSS, the value of PSS, the business model of PSS, and the method of evaluating PSS business models. The QFD technique based and extended approach used to evaluate PSS business models in the design process is subsequently discussed. The following sections describe its application to a case company. Our conclusions, research limitations, and further developments are presented in the last section.

\section{Literature Review}

2.1. Product Service System (PSS). The PSS relates to the result of an innovation strategy, shifting the business model focus from designing and selling physical products only to selling a system of tangible products and intangible services which are jointly capable of fulfilling specific client demands $[20,21]$. Its essence is to add value to products by providing services within the life cycle of products as the functional product-service for customers [22]. In this context, the PSS is a result of strategy, design on all relevant building blocks of business model for implementing an integrated value system of products, services, and communication that are coherent with the medium-long term perspective of profitability and sustainability $[20,22]$. Since value is provided to customers through the functional product-service rather than "pure" product or "pure" service, value concept and its measurement are more important in the design of PSS business models [23]. The current divisions of the PSS are not strictly defined. A classic categorization divides the PSS into three types: product-oriented PSS, use-oriented PSS, and result-oriented PSS [21]. The above three types of PSS are in constant evolution induced by improvements in resource productivity, ownership, and service offerings for getting different levels of value [20]. The method or process for designing business models of PSS is usually required for supporting manufacturers to realize such business model evolutions and get more value and sustainability $[23,24]$.

2.2. The Business Model of PSS. There is no doubt that a good business model can neatly answers several fundamental questions that every manager must ask: "who is the customer? what does the customer value?" and "how do we make money in this business? what is the underlying economic logic that explains how we can deliver value to the customer at an appropriate cost?" [24, 25]. A business model decreases business logic complexity by providing a vision of how a company can derive value from its resources and implement its strategy. Many researchers have tried to do lots of work on defining "what the mean of business models is?" [25-27]. In this paper, we use Chander et al's definition presented in their white paper "The Imperative for Business Model Innovation: A Research and Practice Perspective" as the working definition of PSS business models. A business model of PSS is a holistic, contextualised pattern of attributes (and activities) representing value proposition, value creation, and value capture. It is a specification of the value a company offers to different customer segments and of the architecture 
of the organizational allies for creating, marketing, and delivering this value and relationship capital, to generate profitable and sustainable revenue streams. Value proposition identifies what markets and customer groups (or other beneficiaries) will be targeted and what products. The value creation focuses on how products and services will be created/provided. Finally, value capture relates to the benefits that are realized. Most of the literature agrees that the well-established PSS business models include several dimensions or elements [20] to express the business logic of a specific firm in providing customers with different types of PSS. Typically, dimensions of customer segments, PSS components, PSS characteristics, relationships, and channels are included in the value proposition; key partners, key business processes, and key resources are contained in the value creation; and costs and risk management as well as revenue streams are located in value capture. Different dimensions or different details of the same dimensions can lead to different PSS business models. Consequently, in most firms, there is not just one business model, but many, offering different types of PSS or bundles of product and service (with associated value propositions), with different business model dimensions for delivering these propositions and for capturing the resultant value [24, 26]. The impact of each PSS business model in terms of value to customers, the offering, and required capabilities may be very different, requiring a unified perspective of business model dimensions to aid understanding PSS business models. In many PSS business models, relationships and channels can be substituted or represented by specific services. PSS components and key resources are usually converted to costs structures. Therefore, we consider using PSS characteristics, PSS components, PSS suppliers, enriched SCOR processes (the delivery process of SCOR includes service delivery processes), costs, risk management, and ROI (return on investment) as workable dimensions to identify a design process for PSS business models [24] and to understand how to get a well-designed PSS business model for gaining the best PSS value. It should be noted that the delivery process in SCOR processes is extended to cover all service delivery processes.

2.3. The Value of PSS. The purpose of PS offerings is to generate the best value for customers and organizations involved. However, the producer's sense of value differs from that of the user; that is, there are various forms of value for the same item [28]. In PS offerings, the concept of value is the relative worth, utility, or importance of a PSS [29]. From the perspective of producers, the PSS value is organization value that contains economic value, environmental value, and social value. However, in the design phase of PSS business models, organizations generally consider the economic value. Usually, it can be represented by ROI [19] or the ratio of function to cost. Here, the function is the utility of the tangible products while it is the effect or performance to be achieved for the intangible service [28]. From the perspective of customers, the PSS value is customer value which is constantly changing by the tradeoff between the relevant "gives" and "gets" [30]. It can be measured or calculated by using sacrifice or cost (same meaning as "gives") that customers paid for a PSS and benefit (same meaning as "gets") that customers received based on multidimensional indicators of service or PSS quality (hereafter "quality"). Indicators of quality are becoming more complex and subjective due to more services added in the lifecycle of products [22]. The value of these indicators relies on qualitative characteristics of PSS, and the sacrifice or cost is usually the price of a PSS $[19,28]$. The measurement methods of customer value are divided into two types. The first type is the function of the price and quality. Many functions can be used to calculate the value, such as Linear, Quadratic, Logarithmic, Inverse, and Exponential function [30]. The second type is the mapping that qualities received to costs paid [19]. The first type is usually used to evaluate or improve customer satisfaction in the implementation stage, and the second type is usually used to assist manufacturers to understand customer value demand in the design phase. In this paper, both perspectives of value are integrated in the concept of PSS value for designing the evaluation method. Customer value is represented by the dimensions of prices and quality, and ROI denotes the organization value. Moreover, the second type of measurement methods for customer value is used for aiding evaluation PSS business models.

2.4. The Method of Evaluating PSS Business Models. Business models clearly play an important role in the successful value delivery of PSS. Some studies have tried to develop a workable structured business model framework for the PSS to uncover the business logic of delivering PSS and aid in efficiently designing a PSS business model $[14,15,19]$. Others have provided methods of designing business models for PSS based on structured business model frameworks, such as Business Model Canvas [22, 24]. However, they commonly did not offer a quantitative approach for evaluating PSS business models. Some QFD technique based evaluation method which was developed to evaluate partial dimensions of PSS business models for providing products or services with more value might not be used to directly realize the evaluation and optimization of PSS business models [31]. In addition, considering that the creation of value is the core purpose and central of delivering a PSS or Product Servitised Supply Chain (PSSC), some value-oriented methods, which focused on efficiently evaluating whether a designed PSS or PSSC meets customers' and firms' value demands was proposed. For example, QFD technique based methods were studied to evaluate and optimize a designed PSS component in light of customers' value demands, customers' budgets, and PSS characteristics [16-18]. The $\mathrm{e}^{3}$ value based method is provided to evaluate and optimize the business processes of a PSSC [28]; it can achieve organization's profitability based on the cost arrangement of processes, converting the rate of cost of organizations and $\mathrm{e}^{3}$ value method. However, these models also cannot fully support the evaluation and optimization of PSS business models due to that they only focus on dimensions of value proposition or some partial dimensions of value creation. A holistic value-oriented method which focuses on dimensions related to the whole business logic of 


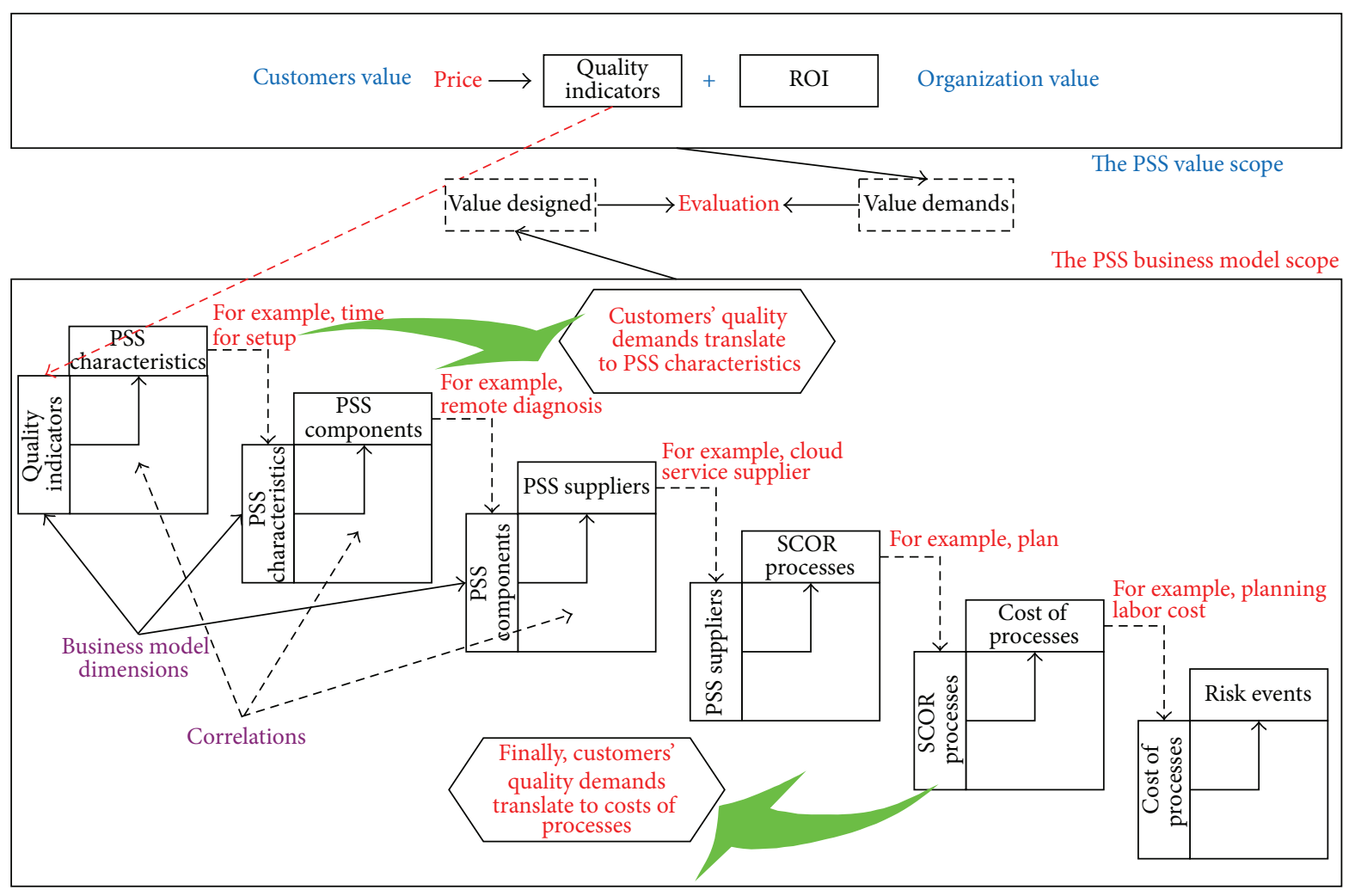

FIGURE 1: The overall evaluation method of PSS business models.

PSS business models for both customers and organizations to efficiently and quantitatively evaluate and optimize PSS business models is still lacking. The absence of a comprehensive method constitutes a source of uncertainty for companies in delivering PS offerings, making it necessary to identify welldesigned PSS business models for sustainable growth and meeting customers' value demands for manufacturing firms [31].

\section{A Value-Oriented Evaluation Method for PSS Business Models}

3.1. The Overall Research Approach. We developed a valueoriented evaluation method for PSS business models to address the key gaps discussed in previous sections. A threestage research approach was adopted as the existing studies in this area remained fragmented. Our research began with the 1st stage literature review to explore the existing methods and techniques relevant to our research focusing mainly on identifying the dimensions of PSS value and PSS business models, a common design process of PSS business models, some QFD technique based evaluation methods, and $\mathrm{e}^{3}$ value based method. The 2nd stage was to develop an evaluation method with several steps to use the design information for quantitatively evaluating PSS business models; and the 3rd stage was to validate the developed method in a real-world context through an in-depth case study with a home application manufacturing company. The theoretical development of our research was not a simple linear process across these three stages. There were actually a lot of iterative learning loops among these three stages to refine the method with case data and to update the case analysis for some more valuable theoretical/practical implications. We decided to structure this paper in a rather straightforward manner to make it easier for readers to follow the main flow of research from the literature review to method development and then case study validation.

The overall logic and rationale underpinning our method development is introduced as follow. In order to effectively and efficiently evaluate design PSS business models, we first need a comprehensive understanding of the key dimensions of PSS value and PSS business models for capturing customers' value demands and the structure of PSS business models and methods that are used in the evaluation step. Second, we need to establish corrections of these dimensions of PSS value and PSS business model by drawing from and extending the QFD technique. As shown in Figure 1, the QFD technique is the basis of the evaluation method. It is used as a multiple-phase approach [18] to establish corrections. This approach consists of six phases of extracting the knowledge of each step of PSS business model design. In essence, this approach gradually translates customers' quality demand into dimensions of PSS business models. The goal of this approach is to establish relationship matrixes (corrections) between customers' quality demand and PSS characteristics, as well as among other PSS business model dimensions. Importance of PSS business model dimensions can be calculated as establishing these matrixes. Then, we can use these corrections to 
The design processes of PSS business models

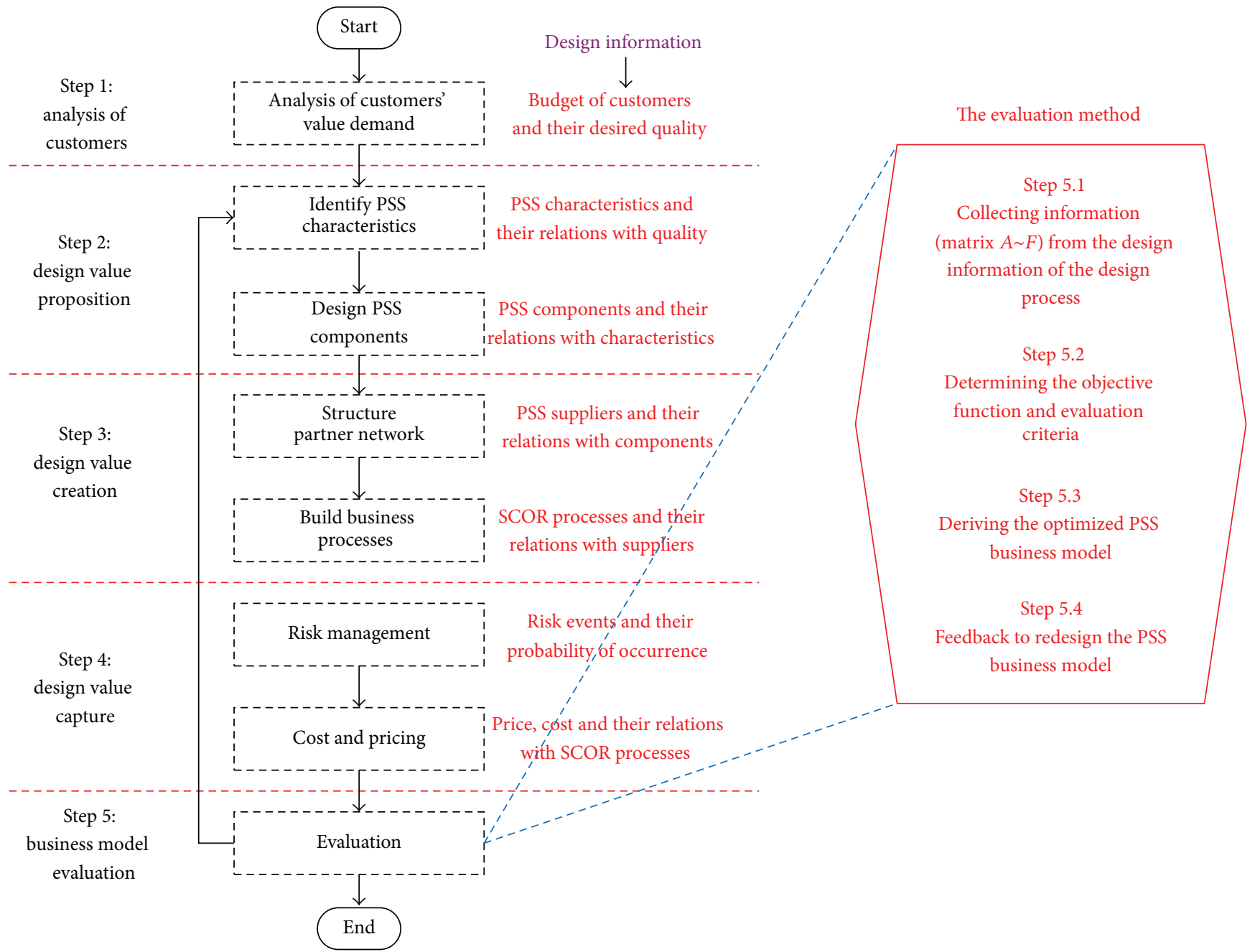

FIGURE 2: The steps of the value-oriented evaluation method.

reflect the designed value of PSS business models and develop an evaluation method integrating the evaluation criteria and objective functions. The developed evaluation method can be used to effectively evaluate whether the designed value of PSS business models is optimized for matching with PSS value demands (customers' value demands and organizations' value demands) and to optimize these PSS business models if the value is not optimized.

\subsection{A Value-Oriented Method for Evaluating and Optimizing} PSS Business Models. A general design process of PSS business models depicted by Figure 2 has been verified in [19] but lacks a concrete method that is used in an evaluation step (Step 5) for evaluating designed PSS business models. The design process takes customers' value demands as inputs to design business model dimensions. The proposed evaluation method is used in Step 5; an optimized business model of PSS for providing appropriate PSS value should be derived from the viewpoints of providers and customers in this step. This means that, based on this step, a derived PSS business model should provide the right quality under the given budget of customers and appropriate economic returns for PSS providers. The value-oriented evaluation method takes the customers' value demand and six matrixes (correlations of business model dimensions) as inputs.

Customers' value demands include the desired quality with its relative importance and the budget of a customer. The quality can be represented by a vector of quality indicators: $Q=\left(q_{1}, q_{2}, \ldots, q_{k}\right)$. The importance of quality is a vector: $W^{q}=\left(w_{1}^{q}, w_{2}^{q}, \ldots, w_{k}^{q}\right)$, and $\sum w_{k}^{q}=1$. The budget of a customer is $P_{\max }$. Customers' value demands can be expressed as $P_{\max } \rightarrow Q$ which expresses the mapping of a customer's budget with its desired quality.

These six matrixes in the following can be produced from the design information and normalized by referencing the QFD technique. All related vectors of these matrixes are row vector.

Definition 1. Matrix $A$ is the correlation of $Q^{T}$ with the vector of PSS characteristics: $H=\left(h_{1}, h_{2}, \ldots, h_{l}\right) . A=\left(a_{i, j}\right)_{k \times l}$, 
where $0 \leq a_{i, j} \leq 1,1 \leq i \leq k$ and $1 \leq j \leq l$, and $\sum_{i=1}^{k} a_{i, j}=1$. Each $a_{i, j}$ denotes the relevancy of related $h_{l} \in H$ and $q_{k} \in Q$. Each $h_{l}$ is relevant with at least one $q_{k}$. The vector $W^{h}$ is the importance vector of PSS characteristics.

Definition 2. Matrix $B$ is the correlation of $H^{T}$ with the vector of PSS components: $O=\left(o_{1}, o_{2}, \ldots, o_{m}\right) . B=\left(b_{i, j}\right)_{l \times m}$, where $0 \leq b_{i, j} \leq 1,1 \leq i \leq l$ and $1 \leq j \leq m$, and $\sum_{i=1}^{l} b_{i, j}=$ 1. Each element $b$ represents relational strength between a characteristic and a component. $W^{o}$ is the importance vector of PSS components.

Definition 3. Matrix $C$ is the correlation of $O^{T}$ with the vector of PSS suppliers: $S=\left(s_{1}, s_{2}, \ldots, s_{n}\right)$ and $S$ must contain the PSS provider itself. $C=\left(c_{i, j}\right)_{m \times n}$, where $0 \leq c_{i, j} \leq 1,1 \leq i \leq m$ and $1 \leq j \leq n$, and $\sum_{i=1}^{m} c_{i, j}=1$. Each element $c$ denotes the degree of responsibility that suppliers should take for a component. $W^{s}$ is the importance vector of PSS suppliers.

Definition 4. Matrix $D$ is the correlation of $S^{T}$ with the vector of SOCR processes: $\mathrm{SP}=\left(\mathrm{sp}_{1}, \mathrm{sp}_{2}, \ldots, \mathrm{sp}_{s}\right) . D=\left(d_{i, j}\right)_{n \times s}$, where $0 \leq d_{i, j} \leq 1,1 \leq i \leq n$ and $1 \leq j \leq s$, and $\sum_{i=1}^{n} d_{i, j}=1$. Each $d_{i, j}$ represents relational relevancy between a supplier and a process. $W^{\text {sp }}$ is the importance vector of SOCR processes.

Definition 5. Matrix $E$ is the correlation of $\mathrm{SP}^{T}$ with the vector of cost metrics of processes: COP $=\left(\operatorname{cop}_{1}, \operatorname{cop}_{2}, \ldots, \operatorname{cop}_{t}\right)$. $E=\left(e_{i, j}\right)_{s \times t}$, where $0 \leq e_{i, j} \leq 1,1 \leq i \leq s$ and $1 \leq j \leq t$, and $\sum_{i=1}^{s} e_{i, j}=1$. Each $e_{i, j}$ denotes relational strength between a process and a cost metric. $W^{\text {cop }}$ is the importance vector of cost metrics.

The cost arrangement for cost metrics of processes is a vector $\mathrm{CM}=\left(\mathrm{cm}_{1}, \mathrm{~cm}_{2}, \ldots, \mathrm{cm}_{t}\right)$; and the total cost of the PSS $C_{t}=\sum \mathrm{cm}_{t}$. The designed price of PSS is $P$.

Definition 6. Matrix $F$ is a correlation of $\mathrm{COP}^{T}$ with the vector of risk events: $R=\left(r_{1}, r_{2}, \ldots, r_{v}\right) . F=\left(f_{i, j}\right)_{t \times v}$, where $0 \leq f_{i, j} \leq 1$. Each $f_{i, j}$ denotes the probability of occurrence of a risk event within a cost metric.

It should be noted that the risk events considered in this paper are the internal risk of the life cycle of PSS delivery; they are mainly related to resource planning, production, service delivery, supply chain management, and operation management. The outside risks, such as market risk, political risks, and technology risk, which should be considered before the design of PSS business models are not considered in the evaluation phase of PSS business models. The occurrence of a risk event will cause the losing cost of organizations. Therefore, matrix $F$ is established to quantify risks from the perspective of losing cost. Risk preventions are becoming the inevitable events of operation management. Consequently, the event of risk preventions turns into a compulsory element in the vector $R$. The value of its corresponding elements $f_{i, j}$ in matrix $F$ is equal to 1 , if at least one more of risk events has a probability of occurrence with the cost metrics that are related to $f_{i, j}$; otherwise $f_{i, j}=0$.
Let $L^{r}=\left(l_{1}^{r}, l_{2}^{r}, \ldots, l_{v}^{r}\right)$ be a corresponding vector of the vector $R$, which represents the set of losing costs caused by the occurrence of risk events in vector $R$. Then, the loss expectation of risk events with each element of the vector CM can be calculated by the following formula:

$$
\begin{aligned}
\mathrm{CM}^{l}=l^{r} \times R^{T}=\left(\mathrm{CM}_{j}^{l} \mid \mathrm{CM}_{j}^{l}=\right. & \left.\sum_{i=1}^{v} l_{i}^{r} \times f_{i, j}\right), \\
& i \in[1, v], j \in[1, t],
\end{aligned}
$$

where $\mathrm{CM}^{l}$ is a vector of loss expectations of the vector CM; it has the same size with CM. These costs cannot directly be used in the value exchange of PSS but surely be used to make sure that the delivery of PSS goes smoothly. Hence, the cost that will be inputted in the value exchange of PSS within the PSS business model can be attained through the following formula:

$$
\begin{aligned}
& \mathrm{CM}^{\prime}=\mathrm{CM}-\mathrm{CM}^{l}=\left(\mathrm{CM}_{i}^{\prime} \mid \mathrm{CM}_{i}-\mathrm{CM}_{i}^{l}\right) \text {, } \\
& i \in[1, t] .
\end{aligned}
$$

Based on the defined matrixes and vectors, the evaluation method (see Figure 2) is designed to consist of the following four steps.

Step 5.1 (collecting knowledge from the design information). The information of $P_{\max }$ and $Q$ is collected from the sales function and CRM (Customer Relationship Management) system. Matrixes $A \sim E$, vectors, price $P$, and total cost $C_{t}$ can be created by the design division. Usually, many different versions of a matrix or an importance vector of a business model dimension may exist, because of that different designers may define different elements for it. For each matrix, an average of these different versions used to represent a comprehensive design of the matrix should be attained by using the following formula:

$$
R_{\mathrm{ave}}=\frac{\sum_{n=1}^{N} R_{n}\left(x_{i, j}\right)}{N}
$$

where $R_{\text {ave }}$ is an attained matrix; $R_{n}\left(x_{i, j}\right)$ are its different versions $\left(x_{i, j}\right.$ are elements of a version); and $N$ is the number of these versions. However, it still needs to be verified that if an attained matrix is accurate in reflecting the correlation between its relative business model dimensions and the design considerations of designers, importance vectors of its relative business model dimensions are used for this problem.

For each importance vector of a business model dimension, lower and upper boundaries for each element of the vector can be identified with its different versions. A synthetical vector of importance with lower and upper boundaries abstracted from these different versions can be specified as

$$
\begin{aligned}
& W^{i *} \\
& \quad=\left(\left(w_{1}^{i *-}, w_{1}^{i *+}\right),\left(w_{2}^{i *-}, w_{2}^{i *+}\right), \ldots,\left(w_{n}^{i *-}, w_{n}^{i *+}\right)\right) .
\end{aligned}
$$

At the same time, the importance vector of a PSS business model dimension can be produced from the relative matrix 
of the dimension and the importance vector of its correlative PSS business model dimension. The calculation formula is shown as follows:

$$
\begin{aligned}
& W^{i}=W^{j} \times R_{\mathrm{ave}}, \\
& w_{n}^{i}=\frac{w_{n}^{i}}{\sum_{n=1}^{N} w_{n}^{i}} \\
& \quad w_{n}^{i} \in W^{i},
\end{aligned}
$$

where $W^{i}$ is the normalized importance vector of a PSS business model dimension; $W^{j}$ is an importance vector of the correlative PSS business model dimension with the previous business model dimension; and $R_{\text {ave }}$ is their correlation matrix. For example, the instantiation formula $W^{h}=W^{q}$. $A$ can be used to calculate the importance vector of PSS characteristics. However, each element of normalized vector $W^{i}$ has deviations with its corresponding element of the synthetical vector $W^{i *}$. And the deviations can be calculated as

$$
\begin{aligned}
& \Delta_{n}^{i-}=w_{n}^{i}-w_{n}^{i *-}, \\
& \Delta_{n}^{i+}=w_{n}^{i *+}-w_{n}^{i} \\
& \quad w_{n}^{i} \in W^{i} \cap\left(w_{n}^{i *-}, w_{n}^{i *+}\right) \in W^{i *},
\end{aligned}
$$

where $\Delta_{n}^{i-}$ is the deviations of $w_{n}^{i}$ from the lower boundary $w_{n}^{i *-}$; and $\Delta_{n}^{i+}$ is the deviations of $w_{n}^{i *+}$ from the upper boundary $w^{i *+}$. Then, a vector of deviations of $W^{i}$ can be derived as

$$
\Delta^{i}=\left(\left(\left|\Delta_{1}^{i-}\right|,\left|\Delta_{1}^{i+}\right|\right),\left(\left|\Delta_{2}^{i-}\right|,\left|\Delta_{2}^{i+}\right|\right), \ldots,\left(\left|\Delta_{n}^{i-}\right|,\left|\Delta_{n}^{i+}\right|\right)\right) .
$$

And then, a normalized deviations vector can be calculated by using the following formula:

$$
\begin{aligned}
\Delta_{n}^{i *-} & =\frac{\Delta_{n}^{i-}}{\max \left(\left|\Delta_{n}^{i-}\right|,\left|\Delta_{n}^{i+}\right|\right)}, \\
\Delta_{n}^{i *+} & =\frac{\Delta_{n}^{i+}}{\max \left(\left|\Delta_{n}^{i-}\right|,\left|\Delta_{n}^{i+}\right|\right)} .
\end{aligned}
$$

The normalized deviations vector is shown in the following:

$$
\begin{gathered}
\Delta^{i *}=\left(\left(\left|\Delta_{1}^{i *-}\right|,\left|\Delta_{1}^{i *+}\right|\right),\left(\left|\Delta_{2}^{i *-}\right|,\left|\Delta_{2}^{i *+}\right|\right), \ldots,\right. \\
\left.\left(\left|\Delta_{n}^{i *-}\right|,\left|\Delta_{n}^{i *+}\right|\right)\right) .
\end{gathered}
$$

Based on the different design considerations of different designers, $\mu$ which represents the designers' preference in lower deviations of elements is introduced to transform deviations of one element to a specific numerical value $\Delta_{n}^{i * \prime}$. The formula for calculating $\Delta_{i}^{i * \prime}$ for each element is shown as follows:

$$
\Delta_{n}^{i * \prime}=\mu \cdot \Delta_{n}^{i *-}+(1-\mu) \times \Delta_{n}^{i *+}
$$

where $1-\mu$ represents the preference of designers in upper deviations. According to formulas (8) and (10), if designers set up different values of $\mu, \Delta_{n}^{i * \prime}$ can have different numerical value and can be classified into three categories:

(i) If $w_{n}^{i}>\left(w_{n}^{i *+}+w_{n}^{i *-}\right) / 2$, then $\mu<\Delta_{n}^{i * \prime}<1$; and if designers prefer that $w_{n}^{i}$ is close to $w_{n}^{i *+}$, then the smaller $\Delta_{n}^{i * \prime}$ the better.

(ii) If $w_{n}^{i}<\left(w_{n}^{i *+}+w_{n}^{i *-}\right) / 2$, then $1-\mu<\Delta_{n}^{i * \prime}<1$; and if designers prefer that $w_{n}^{i}$ is close to $w_{n}^{i *-}$, then the smaller $\Delta_{n}^{i * \prime}$ the better.

(iii) If $w_{n}^{i}=\left(w_{n}^{i *+}+w_{n}^{i *-}\right) / 2$, then $\Delta_{n}^{i * \prime}=1$; and if designers prefer that $w_{n}^{i}$ is in the middle of $w_{n}^{i *-}$ and $w_{n}^{i *+}$, then $\Delta_{n}^{i * \prime}$ should be close to 1 .

Therefore, a transformative deviation vector can be derived and expressed as

$$
\Delta^{i * \prime}=\left(\Delta_{1}^{*^{\prime}}, \Delta_{2}^{*^{\prime}}, \ldots, \Delta_{n}^{*^{\prime}}\right)
$$

The total deviation of a produced importance vector can be calculated by the following formula:

$$
\Delta_{A}^{i * \prime}=\frac{\sum_{n=1}^{N} \Delta_{n}^{i * \prime}}{n},
$$

where $\Delta_{A}^{i * \prime}$ is the total deviation of a produced importance vector. If the designer prefers that more elements of a produced importance vector lie in the first category, then $\Delta_{A}^{i * \prime}$ should be close to $\mu$. If the designer prefers that more elements of a produced importance vector lie in the second category, then $\Delta_{A}^{i * \prime}$ should be close to $1-\mu$. If the designer prefers that more elements of a produced importance vector lie in the third category, then $\Delta_{A}^{i * \prime}$ should be close to 1 . Consequently, if the numerical value of $\Delta_{A}^{i * \prime}$ is not fit with the design considerations of designers, which represents that its relative matrix $R_{\text {ave }}$ may be not accurate in reflecting the correlation between its relative business model dimensions, this relative matrix $R_{\text {ave }}$ should be readjusted until an appropriate value of $\Delta_{A}^{i * \prime}$ is attained. Formulas (3), (6), (8), (12), (14), and (16) are used to abstract available matrixes $A \sim E$ that are the useful knowledge of the design information for evaluating PSS business models.

Step 5.2 (determining evaluation criteria and evaluating PSS business models). According to the concept of customer value, the realization of a customer's desired quality with a lower price than the customer's budget or a higher quality realization than a customer's desired quality under its budget can be seen as an evidence for inferring that the customer's value demand is well met. However, without holding the enough information about the quality realization through implementing the PSS business model in the design phase, new evaluation criteria are needed. In this situation, based on the mapping of the customer's budget to its desired quality: $P_{\max } \rightarrow Q$, a vector of budget distributions on desired quality 
that can be produced from the budget and importance of quality:

$$
f^{p}=P_{\max } \times W^{q}
$$

where $f^{p}$ denotes a desired cost distribution of a customer for all quality indicators. It can be used to assess whether a customer's value demand is met. If the output value of a PSS business model which is expressed by a vector of cost distributions of organizations on quality vector $Q$ derived from matrixes $A \sim E$ and cost arrangement approximates to the $f^{p}$ and the designed price $P$ is lower than $P_{\max }$ or equal to $P_{\max }$, we can infer that this PSS business model properly converts the cost of organizations to the realization of a customer's desired quality and the evaluated PSS business model is feasible and can be further optimized.

However, there are still two issues that need to be solved. First, $P_{\max }$ is bigger than the total cost $C_{t}$. Although $f^{p}$ and the vector of output value have the same size, they cannot be compared because each element of the vector of output value must be smaller than the corresponding element of $f^{p}$. The reason for this situation is that the value-added mechanism is ignored by using these normalized matrixes. According to the value-in-change theory, value-added phenomenon happens in the exchange of PSS components between a supplier and a customer [28]. In this exchange process, a supplier converts its cost to more value during the value creation of delivering PSS components to customers. Each supplier has a capability of cost conversion that is the ratio of the output to input during the value creation; and it is normally greater than 1 and can be determined by the designer. The valueadded mechanism based on the rate of cost conversion of supplier should be characterized as the cost conversion in these matrixes to represent the capital growth. Consequently, matrix $C$ which represents the correlation of suppliers and PSS components may be adjusted based on the capability of cost conversion of suppliers to highlight the value-added mechanism. The adjusted matrix $\mathbf{C}$ is expressed as $\mathbf{C}^{\prime}$, Where $\mathbf{C}^{\prime}=\left(c_{i, j}^{\prime}\right)_{m \times n}, 0 \leq c_{i, j}^{\prime}, 1 \leq i \leq m$, and $1 \leq j \leq n$, and $\sum_{i=1}^{m} c_{i, j} \geq 1$. And the average rate of cost conversion for all providers can be expressed by $\delta$. It can be determined by the designer. It also determines the capability of capital growth of PSS business models and can be designed to make $f^{p}$ and the vector of output value at the same level to be compared. We can get the vector of output value according to matrixes by using the following formula:

$$
f^{o}=\mathrm{CM}^{\prime} \times E^{T} \times D^{T} \times C^{\prime T} \times B^{T} \times A^{T},
$$

where $f^{o}$ is the vector of output value which expresses the transformation of cost to quality through the evaluated PSS business model. It should have the same size with $f^{p}$.

The second issue is how to compare $f^{p}$ and $f^{o}$ for understanding how well they match. Considering that $f^{p}$ and $f^{o}$ have the same size and we focus on the numerical value characteristics of these two vectors, the Euclidean Distance was considered as the criteria for getting the way of similarity of $f^{p}$ and $f^{o}$. Then, the Euclidean Distance between $f^{p}$ and $f^{o}$ is calculated by

$$
d=\sqrt{\left(\sum\left(f_{i}^{p}-f_{i}^{o}\right)^{2}\right)},
$$

where $d$ is the Euclidean Distance; $f_{i}^{p}$ and $f_{i}^{o}$ are elements of $f^{p}$ and $f^{o}$. The value $d$ can be further used to calculate the similarity of $f^{p}$ and $f^{o}$ by using the following formula:

$$
s=\frac{1}{(1+d)},
$$

where $s$ is the similarity that higher numbers would indicate greater realization of quality and the higher degree of satisfaction. However, there are two situations with a numerical value of similarity $s$. One is that most elements of $f^{o}$ may be smaller than their corresponding elements of $f^{p}$ and may approximate them. The other is opposite that most elements of $f^{o}$ may be bigger than their corresponding elements of $f^{p}$ and may also approximate them. Obviously, the latter situation is the target of a well-designed PSS business model. In order to distinguish these two different situations and get the right, the following formula is used:

$$
r=\frac{N_{b}}{L},
$$

where $L$ is the length of $f^{p}$ or $f^{o} ; N_{b}$ is the number of elements of $f^{o}$ that are bigger than their corresponding elements of $f^{p}, 0 \leq N_{b} \leq L ; r$ is the rate of $N_{b}$ to $L, 0 \leq r \leq 1$. Of course, designers want $r$, the bigger the better, in order to expand the satisfaction within a specific numerical value $s$.

Formulas (14) to (17) are used to evaluate PSS business models. If bigger $s$ and bigger $r$ are derived from the evaluation under conditions of the fact that a given price $P$ is no more than customers' budgets and an acceptable ROI returns to organizations, then these evaluated PSS business models are considered to be feasible for being implemented and optimized. These formulas can be used to further optimize them in the next step.

Step 5.3 (deriving the optimized PSS business models). According to formula (14), the realization of both customer value and firm value is determined by the cost arrangement, matrixes, and pricing. As the saying goes, "use the best material at the key point"; with the situation of specific matrixes, the rational cost arrangement can lead to a good quality. When a rational cost arrangement and the capability of capital growth are identified, reasonable pricing can result in good values for both customers and firms. Therefore, the evaluation method should help to make such a balance to get a proper PSS business model by redesigning the cost arrangement, matrixes, and pricing. The target of PSS business models optimization is maximum customer value under an acceptable ROI for organization. This optimization problem may be expressed as

$$
\begin{array}{ll}
\max & s+r \\
\text { s.t. } & C_{t} \times \delta \geq P_{\max }
\end{array}
$$




$$
\begin{aligned}
& r \geq k \\
& P \leq P_{\max } \\
& P-C_{t} \geq R_{d} \\
& \Delta_{A}^{i * \prime} \geq \Delta_{j}^{i},
\end{aligned}
$$

where $R_{d}, k$, and $\Delta_{j}^{i}$ are designed values as the design division's preference. Then, vectors $\mathrm{CM}, H, O, S$, SP, and COP, as well as matrixes $A, B, C^{\prime}, D$, and $E$, can be readjusted to get the optimized PSS business model.

Step 5.4 (feedback to the design process of PSS business models). Four types of useful information are fed back to design division. First, a series of dimensions as an open, and thus promising, business model of PSS for PS offerings can be brought back to such a quantitative evaluation method.

Second, such designed PSS characteristics as having no correlation with any component can be discovered and be seen as "internal" parameters of components. Similarly, impertinent components, providers and processes, and cost metrics can be revealed and readjusted. According to the related information, the design business model can be understood in a new way.

Third, the importance vector of dimensions can be derived. As similar to the importance vector of PSS characteristics $W^{h}$ that is produced from $W^{q}$ and matrix $A$, the importance vector of other dimensions can be calculated. Finally, a rational cost arrangement of cost metrics of processes and pricing of PS offerings can be obtained.

\section{Case Study}

4.1. Case Company. The case company is one of the biggest electronics and home application manufacturers. Nowadays, it is trying to design a PSS business model to provide a solution of electronics and home application with a dozen of services for real estate companies to build intelligent or smart communities. The devices included in this solution can be characterized as investment machines, such as big size LCD (Liquid Crystal Display), intelligent entrance guard, realtime monitoring equipment, and smart home applications. It has also established efficient service organizations and used Information and Communication Technologies (ICT) based platform to supply customized services in combination with devices to offer optimal PSS solutions for customers. These service activities range from maintenance and supplying spare parts to full service contracts, as well as online services using ICT. Yet, it lacked a systematic method to evaluate the designed PSS business model at an early stage of PSS business models development.

\subsection{Results of Application}

Step 5.1 (collecting knowledge from the design information). Related available knowledge abstracted from the CRM system and the design information was collected. Vector $Q$ was obtained through the CRM system with a questionnaire module about quality indicators. Participants were asked to review 15 different quality indicators and rate some of them on a five-point scale for how important they considered them to be. 8 quality indicators which were selected together by 95 percent of participants were considered as the most representative indicators to be included in vector $Q$. Its relative importance $W^{q}$ was identified through the formula $W^{q i}=S^{q i} / \sum_{i=1}^{8} S^{q i}$ for calculating the proportion of the average score of a quality indicator to the sum average score of all quality indicators, where $S^{q i}$ are the average score of each quality indicator. The knowledge abstracted from the CRM system and the design information was briefly shown in Figure 3. Vector $Q$ included "quality of the final product," "PSS flexibility," "physical characteristics of product (size, colour)," "function practicality," "available operation time," "service availability," "service reliability," and "service response speed." A vector of PSS characteristics which included 15 elements was found (Vector $H$ ) (e.g., "time to set up" and "response rate of logistics"). As the Vector O, 28 PSS components were described in Step 2 of the design process. Following with these components, 41 suppliers (Vector $S$ ) were recognized. 162 level 3 processes of SOCR, 25 cost metrics, and 16 risk events were identified. In this application, different budgets $P_{\max }, 24000,28000$, and 40000 (all in a monetary unit), were set to derive optimal PSS business models. Vectors CM and $L^{r}$ were also extracted. We show the results of applying the PSS business model with budget 24000 .

According to formula (3), the initial matrix $A$ of this evaluated PSS business model was built. And all relative importance vectors were synthetized. Matrix $A, W^{q}$, and $W^{h *}$ are shown in the following:

$$
A_{8,15}=\left[\begin{array}{lllllllllllllll}
0.00 & 0.00 & 0.00 & 0.05 & 0.30 & 0.10 & 0.30 & 0.20 & 0.40 & 0.25 & 0.25 & 0.00 & 0.00 & 0.15 & 0.00 \\
0.20 & 0.30 & 0.25 & 0.15 & 0.00 & 0.00 & 0.20 & 0.05 & 0.00 & 0.00 & 0.00 & 0.20 & 0.30 & 0.15 & 0.20 \\
0.00 & 0.10 & 0.00 & 0.00 & 0.25 & 0.30 & 0.00 & 0.00 & 0.10 & 0.00 & 0.25 & 0.40 & 0.10 & 0.00 & 0.00 \\
0.05 & 0.20 & 0.10 & 0.00 & 0.00 & 0.20 & 0.00 & 0.25 & 0.20 & 0.15 & 0.00 & 0.00 & 0.00 & 0.15 & 0.20 \\
0.15 & 0.00 & 0.00 & 0.20 & 0.00 & 0.00 & 0.10 & 0.40 & 0.00 & 0.00 & 0.00 & 0.20 & 0.30 & 0.15 & 0.00 \\
0.00 & 0.25 & 0.35 & 0.00 & 0.15 & 0.00 & 0.10 & 0.00 & 0.00 & 0.20 & 0.25 & 0.00 & 0.20 & 0.00 & 0.20 \\
0.40 & 0.00 & 0.10 & 0.50 & 0.30 & 0.40 & 0.30 & 0.10 & 0.00 & 0.20 & 0.00 & 0.20 & 0.00 & 0.40 & 0.20 \\
0.20 & 0.15 & 0.20 & 0.10 & 0.00 & 0.00 & 0.00 & 0.00 & 0.30 & 0.20 & 0.25 & 0.00 & 0.10 & 0.00 & 0.20
\end{array}\right]
$$




$$
\begin{aligned}
& W^{q}=(0.15,0.15,0.05,0.05,0.10,0.25,0.10,0.15) \\
& W^{h *}=((0.0600,0.6500),(0.0750,0.0800),(0.0850,0.0950),(0.0550,0.0650),(0.0600,0.0700),(0.0400,0.0450) \\
& \quad(0.0700,0.0750),(0.0500,0.5500),(0.0600,0.0650),(0.0750,0.0800),(0.0750,0.0850),(0.0400,0.0500) \\
& \quad(0.0750,0.0800),(0.0500,0.0600),(0.0700,0.0750))
\end{aligned}
$$

Based on the formula (5), $W^{h}$ can be produced from $W^{q}$ and matrix $A$ :

$$
\begin{aligned}
& W^{h} \\
& =(0.0622,0.0767,0.0899,0.0608,0.0661,0.0423,0.0741,0.0529,0.0635,0.0767,0.0794,0.0476,0.0767,0.0569,0.0741)
\end{aligned}
$$

Then, in light of formulas (6) and (8), a normalized deviations vector of $W^{h}$ is attained:

$$
\Delta^{h *}=((0.79,1),(0.51,1),(0.96,1),(1,0.72),(1,0.64)
$$

$$
\begin{aligned}
& (0.85,1),(1,0.22),(1,0.72),(1,0.43),(0.51,1) \\
& (0.79,1),(1,0.32),(0.51,1),(1,0.45),(1,0.22)) .
\end{aligned}
$$

With a designed value $\mu=0.5$ by designers, a transformative deviation vector is acquired according to formula (10):

$$
\Delta^{h * \prime}=(0.895,0.755,0.98,0.86,0.82,0.925,0.61,0.86,0.715,0.755,0.895,0.66,0.755,0.725,0.61) .
$$

Finally, the value of $\Delta_{A}^{h * 1}$ is calculated by using formula (12), where $\Delta_{A}^{h * \prime}=0.788$, and it is bigger than 0.750 which is the smallest acceptable value of $\Delta_{A}^{h * 1}$ (it is set up by designers).
Therefore, matrix $A$ is verified and can be further used to evaluate this PSS business model. Similarly, verified matrixes $B, C^{\prime}, D$, and $E$ are obtained and shown in the following. According to the initial matrix $C^{\prime}$ and vector $\mathrm{CM}, \delta=1.3015$ and $C_{t}=19800$ :

$$
B_{15,28}=\left[\begin{array}{cccccccccccccccccc}
0.00 & 0.00 & 0.05 & 0.00 & 0.00 & 0.10 & 0.00 & 0.10 & 0.00 & 0.00 & 0.05 & 0.00 & 0.10 & 0.10 & \cdots \\
0.05 & 0.00 & 0.00 & 0.00 & 0.10 & 0.00 & 0.00 & 0.00 & 0.05 & 0.05 & 0.00 & 0.20 & 0.00 & 0.00 & \cdots \\
0.00 & 0.10 & 0.00 & 0.00 & 0.15 & 0.10 & 0.10 & 0.00 & 0.00 & 0.00 & 0.00 & 0.00 & 0.00 & 0.00 & \cdots \\
0.05 & 0.00 & 0.10 & 0.25 & 0.00 & 0.10 & 0.00 & 0.05 & 0.10 & 0.10 & 0.10 & 0.00 & 0.10 & 0.05 & \cdots \\
0.00 & 0.00 & 0.15 & 0.00 & 0.00 & 0.10 & 0.05 & 0.00 & 0.00 & 0.10 & 0.10 & 0.10 & 0.10 & 0.05 & \cdots \\
0.10 & 0.15 & 0.00 & 0.05 & 0.00 & 0.00 & 0.00 & 0.00 & 0.00 & 0.10 & 0.15 & 0.00 & 0.00 & 0.00 & \cdots \\
0.00 & 0.00 & 0.00 & 0.00 & 0.00 & 0.00 & 0.00 & 0.00 & 0.00 & 0.20 & 0.10 & 0.10 & 0.10 & 0.10 & \cdots \\
\vdots & \vdots & \vdots & \vdots & \vdots & \vdots & \vdots & \vdots & \vdots & \vdots & \vdots & \vdots & \vdots & \vdots & \vdots
\end{array}\right]
$$




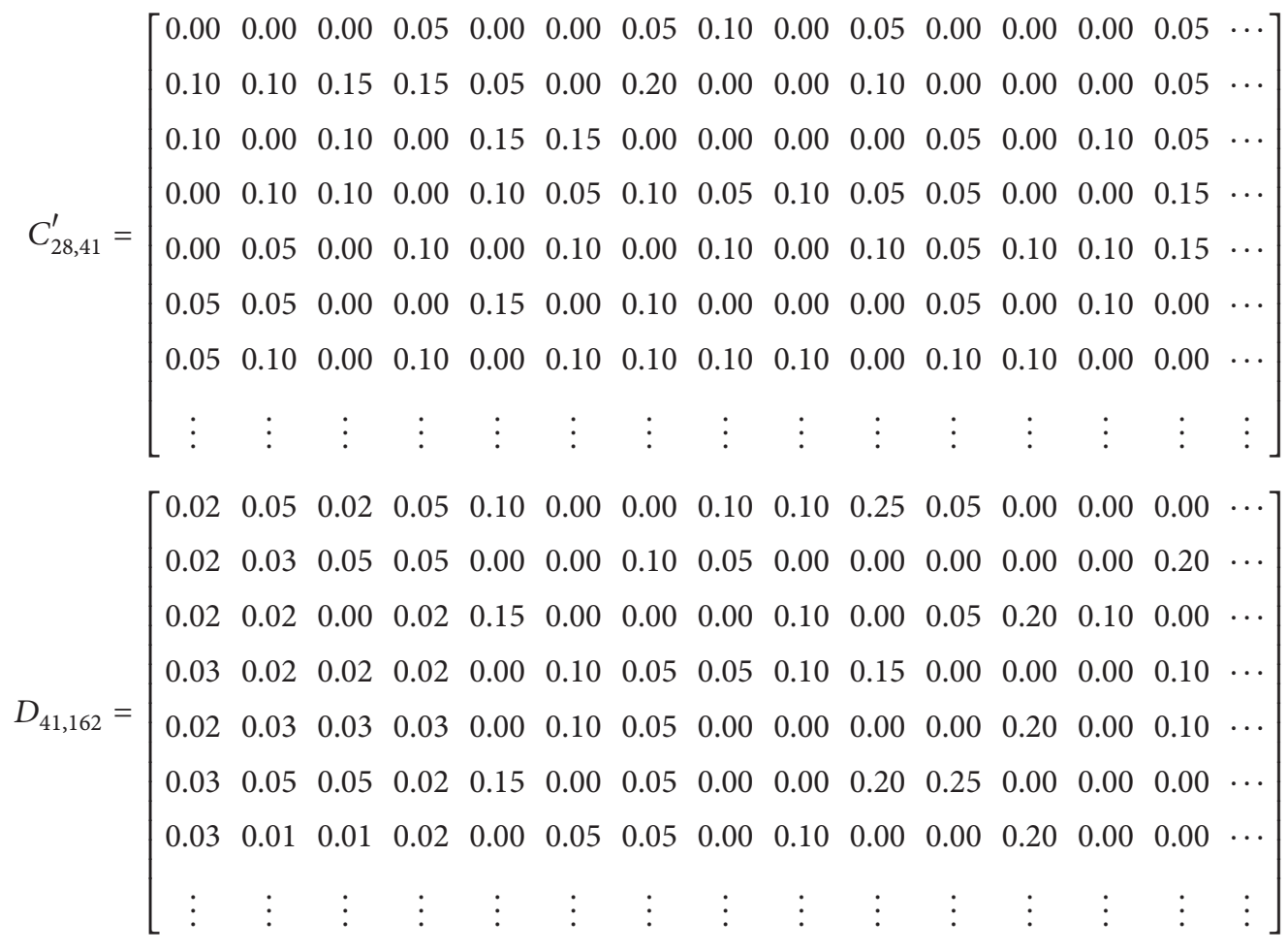

$E_{162,25}=\left[\begin{array}{ccccccccccccccc}0.25 & 0.00 & 0.00 & 0.00 & 0.00 & 0.00 & 0.00 & 0.00 & 0.00 & 0.00 & 0.00 & 0.00 & 0.00 & 0.00 & \cdots \\ 0.00 & 0.00 & 0.25 & 0.00 & 0.00 & 0.00 & 0.20 & 0.50 & 0.00 & 0.00 & 0.00 & 0.00 & 0.00 & 0.10 & \cdots \\ 0.00 & 1.00 & 0.00 & 0.00 & 0.20 & 0.40 & 0.00 & 0.00 & 0.20 & 0.00 & 0.10 & 0.10 & 0.00 & 0.00 & \cdots \\ 0.50 & 0.00 & 0.10 & 0.00 & 0.20 & 0.00 & 0.00 & 0.00 & 0.20 & 0.00 & 0.00 & 0.00 & 0.00 & 0.05 & \cdots \\ 0.00 & 0.00 & 0.00 & 0.00 & 0.00 & 0.00 & 0.00 & 0.00 & 0.00 & 0.00 & 0.00 & 0.10 & 0.00 & 0.05 & \cdots \\ 0.00 & 0.00 & 0.25 & 0.00 & 0.00 & 0.00 & 0.20 & 0.00 & 0.00 & 0.00 & 0.00 & 0.00 & 0.20 & 0.00 & \cdots \\ 0.00 & 0.00 & 0.10 & 0.50 & 0.00 & 0.00 & 0.20 & 0.00 & 0.20 & 0.00 & 0.00 & 0.00 & 0.00 & 0.20 & \cdots \\ \vdots & \vdots & \vdots & \vdots & \vdots & \vdots & \vdots & \vdots & \vdots & \vdots & \vdots & \vdots & \vdots & \vdots & \vdots\end{array}\right]$

$F_{25,16}=\left[\begin{array}{ccccccccccccccc}0.01 & 0.00 & 0.000 & 0.01 & 0.00 & 0.01 & 0.001 & 0.00 & 0.00 & 0.00 & 0.00 & 0.00 & 0.00 & 0.00 & \cdots \\ 0.00 & 0.00 & 0.001 & 0.00 & 0.00 & 0.00 & 0.001 & 0.00 & 0.00 & 0.00 & 0.00 & 0.00 & 0.00 & 0.00 & \cdots \\ 0.00 & 0.01 & 0.001 & 0.00 & 0.00 & 0.00 & 0.001 & 0.00 & 0.01 & 0.00 & 0.10 & 0.00 & 0.00 & 0.00 & \cdots \\ 0.00 & 0.00 & 0.000 & 0.00 & 0.02 & 0.00 & 0.001 & 0.00 & 0.00 & 0.00 & 0.00 & 0.00 & 0.00 & 0.00 & \cdots \\ 0.01 & 0.00 & 0.005 & 0.00 & 0.00 & 0.02 & 0.001 & 0.00 & 0.00 & 0.00 & 0.00 & 0.00 & 0.00 & 0.05 & \cdots \\ 0.00 & 0.00 & 0.005 & 0.00 & 0.00 & 0.00 & 0.001 & 0.01 & 0.00 & 0.00 & 0.00 & 0.00 & 0.00 & 0.00 & \cdots \\ 0.00 & 0.00 & 0.001 & 0.50 & 0.00 & 0.00 & 0.001 & 0.00 & 0.00 & 0.00 & 0.00 & 0.00 & 0.00 & 0.00 & \cdots \\ \vdots & \vdots & \vdots & \vdots & \vdots & \vdots & \vdots & \vdots & \vdots & \vdots & \vdots & \vdots & \vdots & \vdots & \vdots\end{array}\right]$.

Step 5.2 (determining evaluation criteria and evaluating PSS business models) and Step 5.3 (deriving optimized PSS business models). $s$ and $r$ were utilized as criteria. Based on formulas (13) to (17) and these obtained matrixes, the evaluation was implemented by using a spreadsheet program and the simplex algorithm. However, the evaluation result was unsatisfactory. According to formula (18), $R_{d}, k$, and $\Delta_{j}^{i}$ are instantiated with $R_{d}=3000, k=0.6$, and $\Delta_{j}^{i}=0.75$. Then, two times optimization was conducted by the design division for optimizing the tested PSS business model. The optimization results were obtained quickly. The numerical 


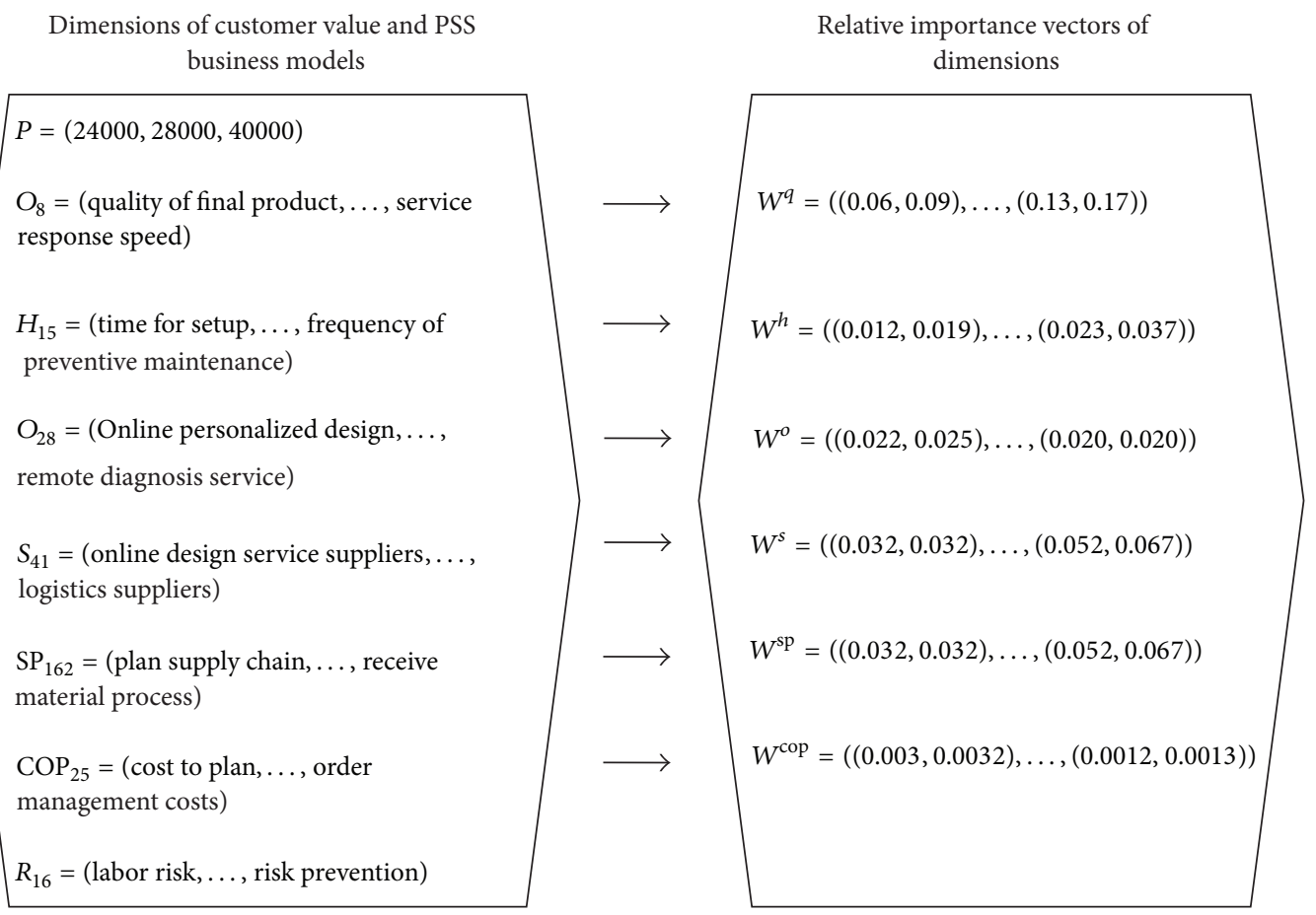

FIGURE 3: The collected knowledge from the design information.

value of vector CM and the size of vector SP were amended at the first time. More cost was assigned to service delivery and some management processes were deleted. Subsequently, matrixes $D$ and $E$ were changed. The result of first optimization was better than the initial evaluation result. Next, based on the first optimization, the size of vector $O$ and $S$ was changed. Some PSS components, such as equipment interconnection and mutual monitoring, remote diagnosis, and on-line maintenance services, were added. Accordingly, service suppliers were changed; and matrixes $B, C^{\prime}$, and $D$ were changed as well. The result of this optimization was even better. All results of evaluation and optimizations are shown in Table 1.

Step 5.4 (feedback to the process of PSS business model design). As the first type information, several vectors of dimensions and their correlations were fed back as a promising PSS business model. An example of the second type was the speed of fault discovery which is removed from the initial designed PSS characteristics, because the faults are discovered immediately based on the equipment interconnection and mutual monitoring service. It cannot be a characteristic that influences the quality. Each importance of vectors was calculated and normalized as the third type of feedback information. Finally, the result of adjustments at the first time can be seen as an example of this kind of information.

4.3. Verification. As shown in Section 4.2., the newly proposed method worked to evaluate a designed PSS business model and get an optimized one. The input from outside of the firm was Vector $W^{q}$ of 8 quality demotions, which was feasible to ask a number of customers through a questionnaire. Other inputs of this method can be collected by design division. However, the creation of these matrixes may be not perceived as a problem, since this information was naturally contained in the design process. It should be noted that the efforts to create matrixes will even decrease in followup studies. Thus, the less effort for creating matrixes would be needed for this method within the comprehensive PSS business model design. The vector $W^{q}$, as well as these matrixes, was also found effective to produce meaningful outcomes. For example, the importance vector of PSS characteristics that derived from the production of $W^{q}$ and $A$ is useful to understand PSS characteristics and aid in redesigning them.

\section{Discussion}

Section 4 showed that the proposed method can support evaluation of different type of PSS business models and identification of appropriate one in practice once the necessary information is available. To a certain extent, this method is capable of substituting a PSS business model analysis and may help overcome the "service paradox" [12]. Alternatively, it can be used to verify results from such analysis or to help understand the nature of PSS business models.

It should be emphasized that the information created for this purpose was only the correlations (matrixes) and cost arrangement which is needed anyway for this economic evaluation in the early stage. The other information was imported from design information about the design process of PSS business models. In addition, that information utilized from the preceding steps is not peculiar to this evaluation method. 
TABLE 1: The results of evaluation and optimizations.

\begin{tabular}{lccc}
\hline $\begin{array}{l}\text { Business model dimensions and optimization } \\
\text { results }\end{array}$ & Initial evaluation & $\begin{array}{c}\text { Evaluation and optimizations } \\
\text { First optimization }\end{array}$ & Second optimization \\
\hline PSS characteristics & 15 & 15 & 17 \\
PSS components & 28 & 28 & 30 \\
PSS suppliers & 41 & 41 & 43 \\
SCOR processes & 162 & 157 & 157 \\
Cost to processes & 25 & 25 & 25 \\
Risk events & 16 & 16 & 16 \\
Average rate of cost conversion $\delta$ & 1.3015 & 1.3320 & 1.3106 \\
The total cost $C_{t}$ & 19800 & 0.8024 & 20000 \\
Similarity $s$ & 0.7533 & 0.500 & 0.8411 \\
Rate $r$ & 0.375 & 22200 & 0.6250 \\
Price of an PS offering $P$ & 21800 & 2600 & 23200 \\
Profit level of an PS offering (for all suppliers) & 2000 & $0.1326 \%$ & 3200 \\
ROI (rate of investment) & $0.1010 \%$ & $0.1600 \%$ \\
\hline
\end{tabular}

In other words, the quality indicators and its importance are fundamental to any PSS business model design, and some correlations may be naturally available if QFD technique is conducted to design PSS business models [17].

This easy-to-learn and easily implemented method is useful serving as a systematic approach to evaluate various PSS business models. Its advantages may be its simplicity and quickness; it can be performed with spreadsheet software or by manually calculating with a pen and paper. To make it even more practical, further attempt is to create a spreadsheet based tool that supports the entire evaluation step, for example, calculations as well as documentation of the results. Some highlighted features are also in line with the general principles that a design support method should fulfil in order to become utilized in industry [16]: (i) be easy to adopt and implement; (ii) facilitate designers to fulfil specified analysis on value requirements with the presumptive condition of PSS business models; (iii) reduce the risk that important elements of PSS business model are forgotten in the design process; and (iv) reduce the total calendar time (from start to end) to solve the evaluation task. One of the scientific advances of this method exists in that it builds quality indicators provided without questioning the customers on the specific quality of individual PS offerings [20]. This is especially an advantage when the PSS business model still exists in the design stage, which makes it virtually impossible in practice to get quality information. This method can address a large number of business model dimensions; in such a case, it can provide more information as its results, such as importance of other dimensions $[15,19]$.

To improve the preciseness of the estimated utility level, investigation of the possibility to adopt a parameter other than the vector of cost distribution of the customer desired quality $f^{o}$ will be a future subject of research. Another in-depth question about this measurement is that if the rate of cost conversion is sufficient to express the value added mechanism of PSS business models. This question is motivated as there might be positive (or "negative") synergy that influences the value added mechanism by organizing multiple suppliers in the implementation of PSS business models.

Finally, the current proposed method focuses on the viewpoint of customer value and organization value. It does not cover the provider's pricing mechanism for feeding back the design of PSS business models or the method of realizing the tradeoff between customer value and organization value as aforementioned discussion; the future version will manage that. In other words, the new method will support decisions, for example, whether to implement the design business model or to contract a supplier with higher capability of cost conversion or to price a lower price than customers' budgets.

\section{Conclusion}

The servitisation literature stresses the role of "PSS business models" as a central element of any servitisation strategy. Despite the importance of these PSS business models, there has not yet been a unified method for evaluating and optimizing them. The existing models focus on a few dimensions (such as dimensions of PS offerings) to evaluate the value delivery of PSS business models and therefore do not reflect or capture the richer picture derived from theory and practice $[19,32]$.

To fill this gap, we have proposed a value-oriented evaluation method that utilizes dimensions of PSS value and multiple dimensions of PSS business model available in the literature. It is important for the following reasons:

(i) The more comprehensive method enables practitioners not only to identify where their current PSS business models lie, but also to understand the wide range of optimized options. We believe that this method will expand the horizons of the managers, 
enabling them to make better choices as they develop their PSS business models.

(ii) Because our method identifies the dimensions of both customer value and organization value, it provides practitioners with knowledge and guidance regarding what needs to be changed to move from one PSS business model to another to get more value.

(iii) Finally, this method may highlight opportunities to quantitatively assess the feasibility of PSS business models and optimize them in the early stage of the design process by using the design information. This method blends the values of customers and organizations and PSS business models; therefore, it helps decision-makers understand the choices and options available.

This new method has formulations that calculate whether the values delivered by PSS business models meet customers' value demands and organizations' value desires by drawing lessons from the QFD technique. Correlations (matrixes) of dimensions of the PSS value and PSS business models are used to convert customer requirements about the quality of the PS offerings to the quality control attributes that are the dimensions of PSS business models; and these dimensions exist throughout the PSS business model design, implementation, and operation link, in order to provide more value as much as possible. In this novel method, the number and size of correlations may vary according to different types of PSS business models and different length of dimensions.

This approach has some advantages and might be used in both B2B and B2C contexts to (i) be effective to evaluate PSS business model by using the design information; (ii) benchmark different PSS business models within the same industry or different markets; and (iii) reduce the risk of elements forgotten and calendar time for evaluation.

Finally, we believe that this method may help managers understand and compare PSS business models, while interpreting and evaluating their differences. We believe this method will enable better design or redesign of PSS business models within various companies, particularly during the design of a business model of PSS; creating this PSS business model is the first fundamental step toward developing formal PS offering able to improve service quality levels, as well as reducing operating costs and investments. This understanding of PSS business models is a central challenge that fosters the introduction of such business model innovations with limited applications. This aspect may be relevant to the sustainability and competitiveness debate because PSS approaches are a promising way to address market and competitive challenges.

This research has some limitations. First of all, it is focused on employing the cost distribution of customers' quality demands and customers' budgets to express customers' value demands, excluding other dimensions. To make the method clear and usable, we decided to limit the dimensions to customers' value demands that are simply provided by a PSS provider to customers. Specifically, we decided to exclude the subjective dimensions that PSS providers may introduce to investigate their PSS business models with customers' value demand, such as "customers' satisfaction."

Additionally, it was decided to create a mode able to capture temporal expansion of dimensions of PSS business models. This type of expansion occurs when companies provide new services that employ new ICT and cover different stages of a product's life cycle (presale, sale, postsale, and dismantling), modifying the type of PSS business models [33]. We excluded the spatial dimension of a PSS business model from our method; this parameter may be important when describing what a company provides when moving into a new type of PSS business models to create a new market.

Moreover the proposed method was a theory building initiative that introduce the QFD technique based method in the evaluation of PSS business models. Further work is needed to test the method empirically, particularly to evaluate the following: (i) the precision of the elements of each correlation, (ii) the conceptual independence of the dimensions of customers' value demands and PSS business models, and (iii) the multiple-dimensional nature of PSS business models.

Furthermore, we observed while studying the real life case that the rate of cost conversion may be not sufficient to express the value-added mechanism of PSS business models. Therefore, as we have considered this point of view in our discussion, in-depth case studies focusing on this mechanism should be undertaken to extend and enrich this approach.

Finally, this model provides a general picture of PSS business models. To a certain extent, this method is capable of helping manufacturers to overcome the "servitisation paradox" according to discovering inconsistencies in PSS business models and optimizing them in the early stage. Future works include perfecting this method further with more cases and developing a general utility tool.

\section{Competing Interests}

The authors declare that there are no competing interests regarding the publication of this paper.

\section{Acknowledgments}

Research works in this paper are supported by the National Natural Science Foundation of China (NSFC) (no. 71571056), the National Key Technology R\&D Program of China (no. 2015BAF04B01-4), and the research projects of the Seventh Framework Programme of the European Union PIRSES-GA2011-295130.

\section{References}

[1] A. Neely, "Exploring the financial consequences of the servitization of manufacturing," Operations Management Research, vol. 1, no. 2, pp. 103-118, 2009.

[2] J.-C. Tu, Y.-C. Huang, C.-Y. Hsu, and Y.-W. Cheng, "Analyzing lifestyle and consumption pattern of hire groups under product service systems in Taiwan," Mathematical Problems in Engineering, vol. 2013, Article ID 710981, 15 pages, 2013. 
[3] T. Baines and H. W. Lightfoot, "Servitization of the manufacturing firm: exploring the operations practices and technologies that deliver advanced services," International Journal of Operations \& Production Management, vol. 34, no. 1, pp. 2-35, 2014.

[4] P. Gaiardelli, B. Resta, V. Martinez, R. Pinto, and P. Albores, "A classification model for product-service offerings," Journal of Cleaner Production, vol. 66, pp. 507-519, 2014.

[5] S. Vandermerwe and J. Rada, "Servitization of business: adding value by adding services," European Management Journal, vol. 6, no. 4, pp. 314-324, 1988.

[6] V. Martinez, M. Bastl, J. Kingston, and S. Evans, "Challenges in transforming manufacturing organisations into productservice providers," Journal of Manufacturing Technology Management, vol. 21, no. 4, pp. 449-469, 2010.

[7] R. De Coster, "A collaborative approach to forecasting productservice systems (PSS)," International Journal of Advanced Manufacturing Technology, vol. 52, no. 9-12, pp. 1251-1260, 2011.

[8] W. A. Neu and S. W. Brown, "Manufacturers forming successful complex business services: designing an organization to fit the market," International Journal of Service Industry Management, vol. 19, no. 2, pp. 232-251, 2008.

[9] F. Ceci and A. Masini, "Balancing specialized and generic capabilities in the provision of integrated solutions," Industrial and Corporate Change, vol. 20, no. 1, pp. 91-131, 2011.

[10] D. Opresnik and M. Taisch, "The value of big data in servitization," International Journal of Production Economics, vol. 165, pp. 174-184, 2015.

[11] H. Gebauer and T. Friedli, "Behavioral implications of the transition process from products to services," Journal of Business and Industrial Marketing, vol. 20, no. 2, pp. 70-78, 2005.

[12] A. Neely, "Why do servitized firms fail?" Operations Management Research, vol. 24, pp. 90-114, 2010.

[13] A. Tukker, "Product services for a resource-efficient and circular economy-a review," Journal of Cleaner Production, vol. 97, pp. 76-91, 2015.

[14] J. Li, F. Tao, Y. Cheng, and L. Zhao, "Big Data in product lifecycle management," The International Journal of Advanced Manufacturing Technology, vol. 81, no. 1-4, pp. 667-684, 2015.

[15] H. Meier and W. Massberg, "Life cycle-based service design for innovative business models," CIRP Annals-Manufacturing Technology, vol. 53, no. 1, pp. 393-396, 2004.

[16] A. Alinezad, A. Seif, and N. Esfandiari, "Supplier evaluation and selection with QFD and FAHP in a pharmaceutical company," The International Journal of Advanced Manufacturing Technology, vol. 68, no. 1-4, pp. 355-364, 2013.

[17] Y.-E. Nahm, H. Ishikawa, and M. Inoue, "New rating methods to prioritize customer requirements in QFD with incomplete customer preferences," The International Journal of Advanced Manufacturing Technology, vol. 65, no. 9-12, pp. 1587-1604, 2013.

[18] C.-T. Wu, T.-S. Pan, M.-H. Shao, and C.-S. Wu, "An extensive QFD and evaluation procedure for innovative design," Mathematical Problems in Engineering, vol. 2013, Article ID 935984, 7 pages, 2013.

[19] T. Sakao and M. Lindahl, "A value based evaluation method for Product/Service System using design information," CIRP Annals-Manufacturing Technology, vol. 61, no. 1, pp. 51-54, 2012.

[20] T. Baines and H. Lightfoot, Made to Serve: How Manufacturers Can Compete through Servitization and Product Service Systems, John Wiley \& Sons, Hoboken, NJ, USA, 2013.
[21] F. H. Beuren, M. G. Gomes Ferreira, and P. A. Cauchick Miguel, "Product-service systems: a literature review on integrated products and services," Journal of Cleaner Production, vol. 47, pp. 222-231, 2013.

[22] A. P. B. Barquet, M. G. de Oliveira, C. R. Amigo, V. P. Cunha, and H. Rozenfeld, "Employing the business model concept to support the adoption of product-service systems (PSS)," Industrial Marketing Management, vol. 42, no. 5, pp. 693-704, 2013.

[23] J. Gao, Y. Yao, V. C. Y. Zhu, L. Sun, and L. Lin, "Service-oriented manufacturing: a new product pattern and manufacturing paradigm," Journal of Intelligent Manufacturing, vol. 22, no. 3, pp. 435-446, 2011.

[24] X. Wu, R. Ma, and Y. Shi, "How do latecomer firms capture value from disruptive technologies? A secondary businessmodel innovation perspective," IEEE Transactions on Engineering Management, vol. 57, no. 1, pp. 51-62, 2010.

[25] C. Zott, R. Amit, and L. Massa, "The business model: recent developments and future research," Journal of Management, vol. 37, no. 4, pp. 1019-1042, 2011.

[26] A. Osterwalder and Y. Pigneur, Business Model Generation: A Handbook for Visionaries, Game Changers, and Challengers, John Wiley \& Sons, New York, NY, USA, 2010.

[27] D. J. Teece, "Business models, business strategy and innovation," Long Range Planning, vol. 43, no. 2-3, pp. 172-194, 2010.

[28] T. He, W. Ho, Y. Zhang, and P. K. Dey, "Organising the business processes of a product servitised supply chain: a value perspective," Production Planning and Control, vol. 27, no. 5, pp. 378-393, 2016.

[29] L. M. Camarinha-Matos and P. Macedo, "A conceptual model of value systems in collaborative networks," Journal of Intelligent Manufacturing, vol. 21, no. 3, pp. 287-299, 2010.

[30] G.-W. Park, K. Park, and M. Dessouky, "Optimization of service value," Computers and Industrial Engineering, vol. 64, no. 2, pp. 621-630, 2013.

[31] Y.-T. Chen and M.-C. Chiu, "A value creation based business model for customized product service system design," in Moving Integrated Product Development to Service Clouds in the Global Economy: Proceedings of the 21st ISPE Inc. International Conference on Concurrent Engineering, September 8-11, 2014, vol. 1 of Advances in Transdisciplinary Engineering, pp. 54-63, IOS Press, 2014.

[32] D. Y. Kong and X. H. Bi, "Impact of social network and business model on innovation diffusion of electric vehicles in China," Mathematical Problems in Engineering, vol. 2014, Article ID 230765, 7 pages, 2014.

[33] U. Gelbmann and B. Hammerl, "Integrative re-use systems as innovative business models for devising sustainable productservice-systems," Journal of Cleaner Production, vol. 97, pp. 5060, 2015. 


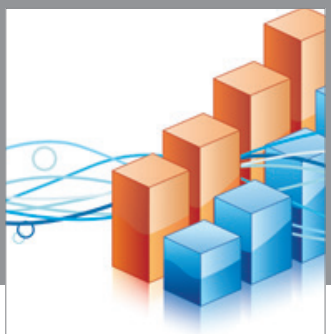

Advances in

Operations Research

vatem alat4

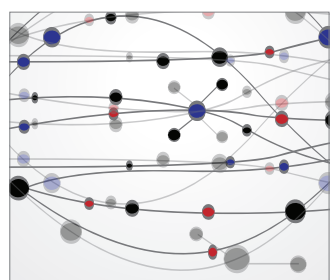

\section{The Scientific} World Journal
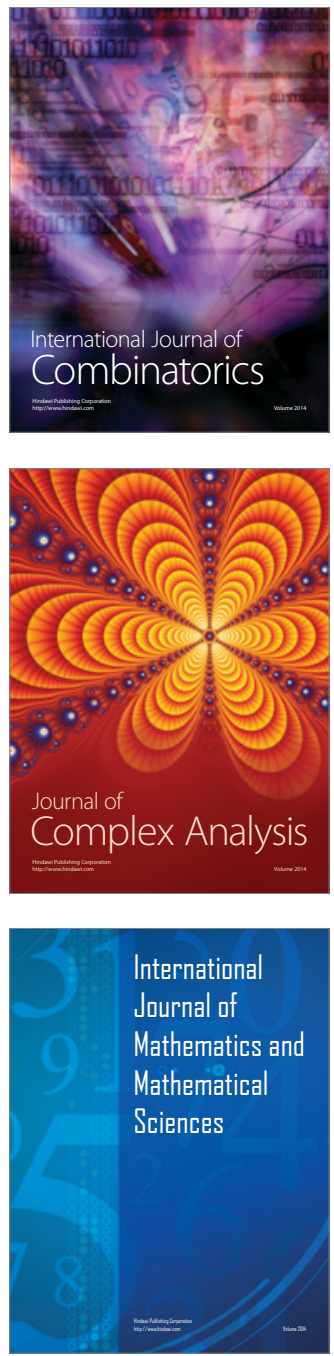
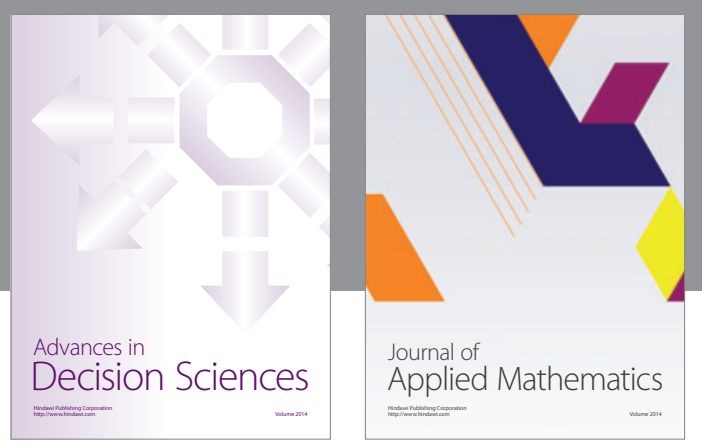

Algebra

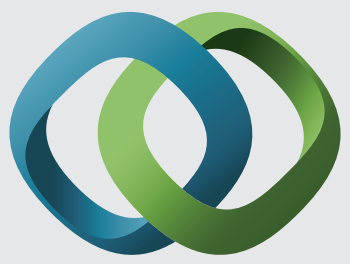

\section{Hindawi}

Submit your manuscripts at

http://www.hindawi.com
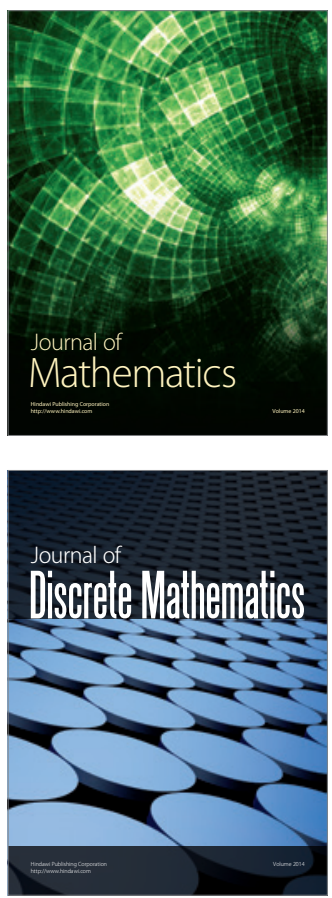

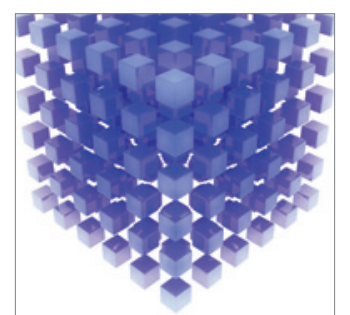

Mathematical Problems in Engineering
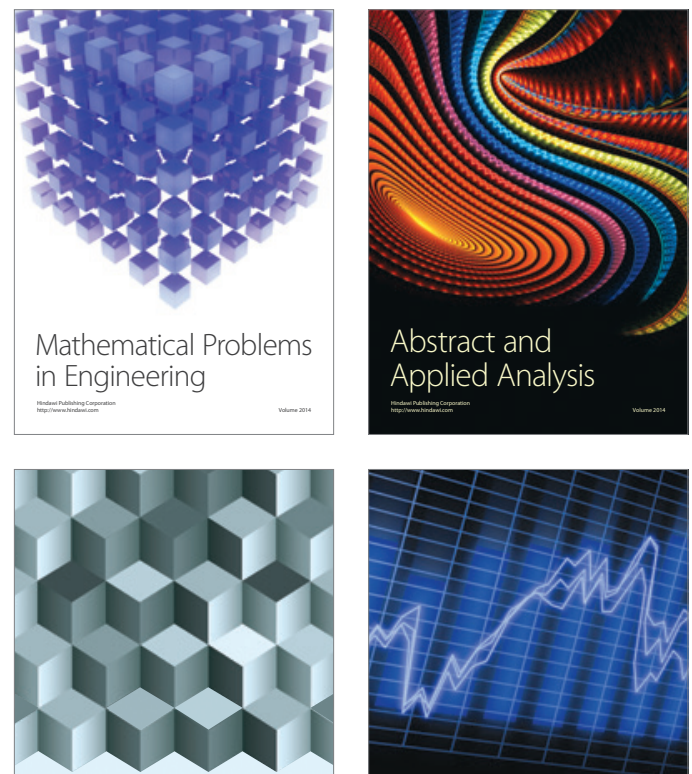

Journal of

Function Spaces

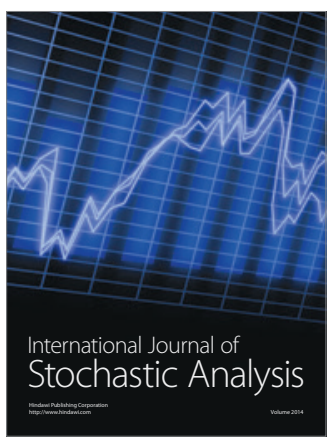

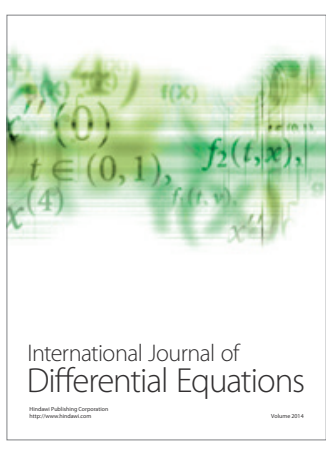
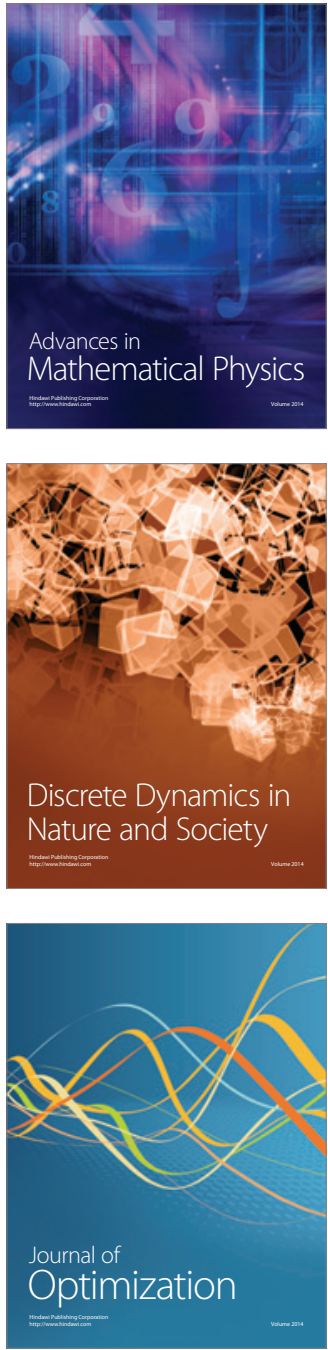